\title{
Capecitabine inhibits epithelial-to-mesenchymal transition and proliferation of colorectal cancer cells by mediating the RANK/RANKL pathway
}

\author{
MINGHAI SHAO $^{1}$, CAIPING JIANG ${ }^{1}$, CHANGHUI YU $^{1}$, \\ HAIJIAN JIA $^{1}$, YANLI WANG ${ }^{1}$ and XINLI MAO ${ }^{2}$ \\ Departments of ${ }^{1}$ Radiation Oncology and ${ }^{2}$ Gastroenterology, Key Laboratory of Minimally Invasive Techniques and \\ Rapid Rehabilitation of Digestive System Tumor of Zhejiang Province, Taizhou Hospital of Zhejiang Province \\ Affiliated to Wenzhou Medical University, Linhai, Zhejiang 317000, P.R. China
}

Received March 12, 2021; Accepted October 6, 2021

DOI: 10.3892/ol.2022.13216

\begin{abstract}
Colorectal cancer (CRC) is the third most prevalent malignancy globally. Capecitabine is an important form of chemotherapy for colorectal cancer. The present study aims to investigate the underlying mechanism of action of the drug in CRC cells. In the present study, 50 pairs of CRC and adjacent normal tissues were collected, and CRC cell lines (SW480, SW620, HT29, LOVO and HCT116) and NCM460 colonic epithelial cells were also purchased and used. Western blotting was used to measure the expression levels of proteins involved in the receptor activator of nuclear factor- $\kappa \mathrm{B}(\mathrm{RANK}) /$ receptor activator of nuclear factor- $\kappa \mathrm{B}$ ligand (RANKL) pathway and epithelial-to-mesenchymal transition (EMT), including RANK, RANKL, osteoprotegerin (OPG), E-cadherin, vimentin and $\mathrm{N}$-cadherin. Proliferation and migration were measured using MTT, Cell Counting Kit-8, EdU, Transwell and wound healing assays, respectively. In the present study, it was found that the RANK/RANKL pathway was activated in cancer tissues and cells. Additionally, it was observed that capecitabine treatment reduced the protein expression of RANK, RANKL and OPG in HT29 cells, suggesting that capecitabine has a repressive effect on the RANK/RANKL pathway. Furthermore, functional experiments revealed that the proliferative ability and the EMT process observed in HT29 cells were inhibited after they were treated with
\end{abstract}

Correspondence to: Dr Xinli Mao, Department of Gastroenterology, Key Laboratory of Minimally Invasive Techniques and Rapid Rehabilitation of Digestive System Tumor of Zhejiang Province, Taizhou Hospital of Zhejiang Province Affiliated to Wenzhou Medical University, 150 Ximen Street, Linhai, Zhejiang 317000, P.R. China E-mail: maoxinlimr@163.com

Key words: colorectal cancer, capecitabine, receptor activator of nuclear factor- $\kappa \mathrm{B} /$ receptor activator of nuclear factor $-\kappa \mathrm{B}$ ligand pathway, epithelial mesenchymal transition, therapeutic target capecitabine or transfected with si-RANK. Rescue assays were then performed, which revealed that the promotion of RANK via transfection of cells with $50 \mathrm{nM}$ pcDNA3.1-RANK reversed the inhibitory effects of capecitabine on HT29 cell proliferation and EMT. These findings suggest that the regulatory role of capecitabine is at least partially mediated through the RANK/RANKL pathway in colorectal cancer. The present study demonstrated that capecitabine-induced repression of CRC is exerted by inhibiting the RANK/RANKL pathway, where this new mechanism potentially provides a novel therapeutic target.

\section{Introduction}

Colorectal cancer (CRC) is one of the most prevalent malignancies worldwide, and according to the global cancer statistics in 2012, it has high rates of morbidity $(9.7 \%)$ and mortality $(8.5 \%)(1,2)$. The occurrence of CRC is the result of the interaction of multiple factors, and its pathology causes include unhealthy lifestyle, high-fat and high-protein diet, carcinogenic environment, and chromosome instability (3-5). Although there has been advances made in the diagnostic and treatment strategies for CRC treatment, the survival rate from this type of cancer remains low due to the complex pathology of the disease (6).

At present, treatment for CRC mainly consists of surgery supplemented by chemotherapy (5-fluorouracil, oxaliplatin, irinotecan and capecitabine), which can achieve satisfactory therapeutic effects (7-9). However, a lack of effective treatment methods remain for patients with advanced-stage CRC tumors (7). Chemotherapy is one method that is currently in use for patients with cancer, including CRC (10). Therefore, discovering novel agents and analyzing their mechanism of action in relation to the occurrence and development of CRC has important implications for the development of novel therapies (11).

To increase the therapeutic efficacy of chemotherapy in colorectal cancer, the search for downstream effectors is required. In particular, capecitabine is typically administered as a combinational chemotherapy (with surgery) or as 
a monotherapy for CRC treatment (9). It preferentially generates 5-flurouracil (5-FU) which represents a well-established treatment method (12). Due to the acquisition of chemotherapy resistance, capecitabine treatment frequently fails in CRC $(13,14)$. Therefore, interrogation of new effectors associated with its treatment is required to potentially discover novel therapeutic targets.

The receptor activator of nuclear factor- $\kappa \mathrm{B}$ (RANK) and RANK ligand (RANKL) are two important components of the RANK/RANKL pathway (15). RANK and RANKL are both members of the TNF superfamily of receptors and is regulated by osteoprotegerin (OPG), which is a decoy receptor for RANKL that prevents its binding to its receptor RANK (16). This pathway exerts its function in differentiating microfold cells by recruiting TNF receptor-associated factor adaptor proteins and activating downstream pathways, such as the NF- $\kappa$ B and EMT pathways (17-19). Several studies have reported dysregulation and function of this pathway in a number of cancers. RANK and c-Met-regulated pathways have been reported to enhance metastatic colonization in prostate cancer (20). In addition, the RANKL/RANK/MMP-1 pathway was found to contribute to the metastasis of breast and prostate cancer cells (21). RANK/RANKL can also be exploited as a target for the treatment of myeloma and solid tumors, such as prostate and breast cancer (22). In tissues from liver (23), stomach (24), breast (25), thyroid (26), prostate (27) and pancreatic cancers (28), high levels RANK expression were previously detected, suggesting that RANK may be involved in the occurrence and development of malignant tumors. Therefore, RANK may apply a multitude of mechanisms to facilitate the tumorigenic process. Although the role of RANK in a variety of malignant tumors has been previously studied, its possible oncogenic role in CRC and its significance in occurrence remain unclear, where there are few reports. These reports only mentioned that RANK promotes CRC migration and invasion, and it may be related to the relapse risk of stage II CRC $(29,30)$.

In the present study, the possible oncogenic effectors associated with capecitabine in CRC were investigated. The expression levels of components in the RANK/RANKL pathway in CRC tissues and cell lines were measured, where the roles of capecitabine and the RANK/RANKL pathway were investigated. Finally, the potential effects of capecitabine on the RANK/RANKL pathway in CRC cells were also studied.

\section{Materials and methods}

Tissue samples. In the present study, 50 pairs of CRC $(>1.5 \mathrm{~cm}$ away from the negative tumor margin) and adjacent normal tissues were collected from January to December 2019 and stored at $-80^{\circ} \mathrm{C}$. Western blotting was applied to detect the expression levels of RANK, RANKL and OPG. These tissue samples were procured after surgical excisions of tissues from patients with CRC at the Taizhou Hospital of Zhejiang Province affiliated to Wenzhou Medical University (Linhai, China). Patients had a pathological diagnosis of CRC according to the Chinese Protocol of Diagnosis and Treatment of Colorectal Cancer (2020 edition) (31) and did not undergo any pre-operative treatment, and each patient had provided appropriately signed consent forms. The clinicopathological features of patients were listed in the Table SI, and the average age was $61.16 \pm 7.46$ years and the proportion of male patients was $60 \%$. The Ethics Committee of Taizhou Hospital of Zhejiang Province affiliated to Wenzhou Medical University reviewed and approved the present study (approval no. ZXC2019005; Linhai, China).

Patient inclusion and exclusion criteria. The inclusion criteria were: i) Age $\geq 40$ years and $\leq 80$ years; ii) colorectal adenocarcinoma was confirmed by colonoscopy and biopsy before surgery; iii) no tumor metastasis or implantation in adjacent organs was found in preoperative CT imaging evaluation; and iv) obtained the patients' informed consent and they were willing to cooperate. The exclusion criteria were: i) Age $<40$ years; ii) cases of emergency operation due to acute intestinal obstruction, perforation or bleeding; iii) combined with malignant tumors of other organs; iv) CT examination confirmed that the tumor invaded adjacent organs or distant metastasis, which made it impossible to perform radical resection; v) contraindications of laparoscopic surgery; and vi) unwilling to cooperate and poor compliance.

Cell lines and treatment. CRC cell lines SW480, SW620, LOVO, HT29 and HCT116 and normal control cells (colonic epithelial cell NCM460) were from American Type Culture Collection. They were cultured in DMEM (Nanjing KeyGen Biotech Co., Ltd.) supplemented with 10\% FBS (Gibco; Thermo Fisher Scientific, Inc.) and $1 \%$ antibiotics $(100 \mu \mathrm{g} / \mathrm{ml}$ streptomycin and $100 \mathrm{U} / \mathrm{ml}$ penicillin; Invitrogen; Thermo Fisher Scientific, Inc.). These cells were maintained in a humidified atmosphere under $5 \% \mathrm{CO}_{2}$ at $37^{\circ} \mathrm{C}$ for subsequent assays. Different concentrations of capecitabine $(25,50,100$, 200 and $400 \mu \mathrm{M}$; Shanghai Roche Pharmaceuticals Co., Ltd.) were applied to the CRC cells (HT29, SW480, SW620, LOVO and HCT116) for $48 \mathrm{~h}$ at $37^{\circ} \mathrm{C}$.

Cell transfection. CRC cells (HT29, SW480, SW620, LOVO and HCT116) were divided into the si-RNA negative control (NC; Guangzhou RiboBio Co., Ltd.), si-RANK, pcDNA3.1 vector (Thermo Fisher Scientific, Inc.) and pcDNA3.1-RANK groups. pcDNA3.1-RANK was constructed as follows: Firstly, primers were designed according to the complete sequence of RANK gene in the GenBank (https://www.ncbi.nlm.nih.gov/genbank/; sense, 5'-GGCTGGCTACCACTGGAACT-3' and antisense, 5'-TCCTGTAGTAAACGCCGAAGA-3'). Then, the restriction endonucleases BamHI and XhoI (Promega Corporation) were added to the 5 ' ends of the sense and antisense primers, respectively. The DNA was extracted from HT29 cells with DNA Extraction Reagent (cat. no. P1012; Beijing Solarbio Science \& Technology Co., Ltd.), and then the RANK gene was amplified by PCR with 2X Taq plus MasterMix (cat. no. BL553B; Biosharp; Beijing Labgic Co., Ltd.). The thermocycling conditions were as follows: Initial denaturation at $94^{\circ} \mathrm{C}$ for $2 \mathrm{~min}$; followed by denaturation at $94^{\circ} \mathrm{C}$ for $30 \mathrm{sec}$, annealing at $60^{\circ} \mathrm{C}$ for $30 \mathrm{sec}$ and extension at $72^{\circ} \mathrm{C}$ for $1 \mathrm{~min}$ for 30 cycles; and extension at $72^{\circ} \mathrm{C}$ for $5 \mathrm{~min}$. A $1 \%$ agarose gel was prepared, the amplified DNA was electrophoresed, and the gel dyed with ethidium bromide was observed under an ultraviolet lamp. Afterwards, the PCR recovered product and pcDNA3.1(+) 
vector were purified by double enzyme digestion with BamHI and $\mathrm{XhoI}$. Afterwards, T4 DNA ligase (Promega Corporation) was added to the centrifuge tube and ligated overnight in a $16^{\circ} \mathrm{C}$ water bath. The ligation product was transformed into competent DH5 $\alpha$ Escherichia coli and grown on the selective LB solid medium (containing $100 \mu \mathrm{g} / \mathrm{ml}$ ampicillin; Gibco; Thermo Fisher Scientific, Inc.). The recombinant plasmids of the positive clones were extracted, digested with BamHI and $\mathrm{XhoI}$, and then subjected to agarose gel electrophoresis for further sequencing and identification. The si-NC and pcDNA3.1 vector groups served as control groups. Cells were transfected with $50 \mathrm{nM}$ si-NC, si-RANK, pcDNA3.1 vector or pcDNA3.1-RANK using Lipofectamine ${ }^{\circledR} 2000$ (Gibco; Thermo Fisher Scientific, Inc.) according to the manufacturer's protocols. The si-NC (sense, 5'-UAGCGACUAAAC ACAUCAAUU-3' and antisense, 5'-UUAUCGCUGAUU UGUGUAGUU-3'), si-RANK (sense, 5'-CCAAGGAGGCCC AGGCUUAUU-3' and antisense, 5'-UAAGCCUGGGCCUCC UUGGUU-3'), pcDNA3.1 and pcDNA3.1-RANK vectors were transfected at $37^{\circ} \mathrm{C}$ for $48 \mathrm{~h}$. Afterwards, the cells were cultured at $37^{\circ} \mathrm{C}$ for $24 \mathrm{~h}$ before they were used for subsequent experiments.

$R N A$ isolation and reverse transcription-quantitative $P C R$ $(R T-q P C R)$. Total RNA was extracted from CRC cells (HT29, SW480, SW620, LOVO and HCT116) using a UNIQ-10 Column Trizol Total RNA Isolation Kit (cat. no. B511321-0100; Sangon Biotech Co., Ltd.). The RNA samples were quantified and then reverse-transcribed using Reverse Transcriptase M-MLV (cat. no. 28025013; Thermo Fisher Scientific, Inc.). The conditions were as follows: $37^{\circ} \mathrm{C}$ for $10 \mathrm{~min}, 42^{\circ} \mathrm{C}$ for $50 \mathrm{~min}$ and $95^{\circ} \mathrm{C}$ for 5 min. qPCR was performed using TB Green ${ }^{\mathrm{TM}}$ Premix Ex Taq ${ }^{\mathrm{TM}}$ II (Tli RNaseH Plus; Takara Bio, Inc.). The following primer sequences were used in the present study: RANK forward, 5'-AGCATTGTTAGAGCCTGTGG-3' and reverse, 5'-CAGACGTGGCAGGACTAAGG-3' and GAPDH forward, 5'-CCATGGGGAAGGTGAAGGTC-3' and reverse, 5'-AGTGATGGCATGGACTGTGG-3'. The thermocycling conditions were as follows: Initial denaturation at $95^{\circ} \mathrm{C}$ for $3 \mathrm{~min}$, followed by each step of denaturation at $95^{\circ} \mathrm{C}$ for $10 \mathrm{sec}$ and annealing extension at $58^{\circ} \mathrm{C}$ for $30 \mathrm{sec}$, for 35 cycles. The $2^{-\triangle \Delta C q}$ method was applied to calculate the relative RANK mRNA expression level (32), and GAPDH was used as the reference gene.

MTT assay. Cell viability was evaluated using MTT as previously described (33). A total of $1 \times 10^{4}$ HT29 cells were seeded into 96-well culture plates and subsequently grown overnight at $37^{\circ} \mathrm{C}$. Next, $10 \mu \mathrm{l}$ MTT at a concentration of $5 \mathrm{mg} / \mathrm{ml}$ was added into each well and incubated at $37^{\circ} \mathrm{C}$ for a further $4 \mathrm{~h}$. DMSO was used to dissolve the formazan crystals. The absorbance at $540 \mathrm{~nm}$ in each well was then measured using a Multiplate reader (Tecan Group, Ltd.), which was normalized to the absorbance values of untreated cells at the corresponding time points $(12,24,36,48$ and $60 \mathrm{~h})$.

Cell Counting Kit-8 (CCK-8) assay. Referring to the protocol of the CCK-8 (cat. no. C0038; Beyotime Institute of Biotechnology), NCM460, SW480, SW620, LOVO, HT29 and HCT116 cells $\left(2 \times 10^{4}\right.$ cells/well) were inoculated into 96-well plates. Afterwards, $20 \mu \mathrm{l}$ CCK-8 solution and $100 \mu \mathrm{l}$ DMEM (with 10\% FBS) were added and cells were incubated for $1 \mathrm{~h}$. The absorbance values at $450 \mathrm{~nm}$ were measured by a microplate reader (Tecan Group, Ltd.).

EdU staining. Cell proliferation was measured using an EdU assay kit (Guangzhou RiboBio Co., Ltd). Briefly, stably transfected HT29 cells $\left(2 \times 10^{3}\right.$ cells/well) were seeded into 96-well culture dishes. After cell culture overnight, $10 \mathrm{nM}$ EdU was supplemented and cells were cultured for a further $12 \mathrm{~h}$ at $37^{\circ} \mathrm{C}$. They were then washed with PBS, fixed in $4 \%$ paraformaldehyde for $30 \mathrm{~min}$ at $37^{\circ} \mathrm{C}$, and stained with Apollo ${ }^{\circledR}$ Fluorescent dye solution (cat. no. C10310-3; Guangzhou RiboBio Co., Ltd.) for $30 \mathrm{~min}$ at $37^{\circ} \mathrm{C}$. The Apollo ${ }^{\mathrm{R}}$ Fluorescent dye solution was discarded, and then $0.1 \mathrm{ml} 0.5 \%$ Triton X-100 was added for $10 \mathrm{~min}$ at room temperature. Afterwards, the TritonX-100 was discarded, and $0.1 \mathrm{ml} 1 \mathrm{mg} / \mathrm{ml}$ DAPI solution (cat. no. C0060; Beijing Solarbio Science \& Technology Co., Ltd.) was added for $5 \mathrm{~min}$ at $37^{\circ} \mathrm{C}$. In total, three randomly selected fields were imaged using a fluorescence microscope (Olympus IX73; Olympus Corporation) and cells exhibiting blue fluorescence were defined as positive and counted using the ImageJ software v1.8 (National Institutes of Health). The ratio of the positive cell number/total cell number is a measure of the relative EdU incorporation rate.

Transwell assay. The 24-well Millicell uncoated chambers were used for the measurement of cell migration. At 2 days post-transfection, cancer cells ( $3 \times 10^{5}$ cells) grown in serum-free DMEM were placed into the upper compartment $(8-\mu \mathrm{m}$ pore size; EMD Millipore) whereas the lower compartment was filled with $500 \mu \mathrm{l}$ DMEM and 15\% FBS. In total, $24 \mathrm{~h}$ later at room temperature, non-migratory cells were discarded, whilst migratory cells were fixed using cold $98 \%$ ethanol at $37^{\circ} \mathrm{C}$ for $10 \mathrm{~min}$ and stained with $0.1 \%$ Crystal Violet at $37^{\circ} \mathrm{C}$ for $20 \mathrm{~min}$. At the end of the experiment, five visual fields were randomly selected, and then stained cells were counted using an inverted light microscope (Nikon Corporation). Relative cell migration $(\%)=($ migrated cell number of treatment group/migrated cell number of DMSO group) x100\%.

Wound healing assay. Wound healing assays were performed also for the assessment of cell migration. Cells were plated into six-well plates $\left(5 \times 10^{4}\right.$ cells per well) with DMEM. A sterilized $5-\mu 1$ plastic micropipette was then used to make a scratch on the surfaces of cell monolayers at $90 \%$ confluency. The cells were incubated under standard conditions $\left(5 \% \mathrm{CO}_{2} ; 37^{\circ} \mathrm{C}\right.$; DMEM; $1 \%$ antibiotics) for $24 \mathrm{~h}$ and then washed three times with PBS. The wound regions at different time points ( 0 and $24 \mathrm{~h})$ were imaged and photographed using an IX71 inverted light microscope (Olympus Corporation). Cell migration rate $=($ cell migration distance of treatment group/cell migration distance of control group) $\times 100 \%$, and cell migration distance referred to the distance that cells migrated between 0 and $24 \mathrm{~h}$.

Western blotting. Expression levels of proteins in the RANK/RANKL pathway and in the epithelial-to-mesenchymal transition (EMT) process of CRC cells (HT29, SW480, SW620, LOVO and HCT116) were analyzed by western blotting. In the present study, RIPA buffer (cat. no. P0013B; 
Beyotime Institute of Biotechnology) was used to obstain cell protein lysates. First, the cells were trypsinized and then centrifuged at $134 \mathrm{xg}$ at $37^{\circ} \mathrm{C}$ for $5 \mathrm{~min}$. Next, the supernatant was removed and the cell pellet was washed three times with cold PBS. The cell lysates were produced by the addition of $100 \mu 1$ RIPA buffer and incubated on ice for $1 \mathrm{~h}$. The samples were sonicated $(80 \mathrm{~W}$ ultrasonic power; $2 \mathrm{sec}$ working time and $4 \mathrm{sec}$ interval time) for $3 \mathrm{~min}$ on ice and centrifuged at $12,000 \mathrm{x} \mathrm{g}$ for $12 \mathrm{~min}$ at $4^{\circ} \mathrm{C}$. A BCA protein assay kit (Abcam) was used to determine the protein concentration according to the manufacturer's protocols. In total, $25 \mu \mathrm{g}$ protein was loaded into each lane of a $10 \%$ Mini-PROTEAN ${ }^{\circledR}$ TGX Stain-Free ${ }^{\mathrm{TM}}$ Protein gel with electrophoresis buffer $(25 \mathrm{mM}$ Tris, $0.192 \mathrm{M}$ glycine, $0.1 \% \mathrm{SDS}$ ) and run for $0.5 \mathrm{~h}$ at $200 \mathrm{~V}$. After the proteins were separated, they were transferred onto Trans-Blot ${ }^{\circledR}$ Turbo $^{\mathrm{TM}}$ Mini PVDF membranes and blocked in $1 \%$ BSA (Abcam) for $3 \mathrm{~h}$ at $37^{\circ} \mathrm{C}$. The membranes were then incubated with relevant the primary antibodies (RANK, dilution, 1:1,000; cat. no. ab200369; RANKL, dilution, 1:1,000; cat. no. ab9957; OPG, dilution, 1:1,000; cat. no. ab73400; E-cadherin, dilution, 1:1,000; ab40772; vimentin, dilution, 1:1,000; ab92547; N-cadherin, dilution, 1:1,000; ab18203; GAPDH, dilution, 1:2,000; ab9485; Abcam) overnight at $4^{\circ} \mathrm{C}$. The next day, TBS-T $(5 \%$ blocking buffer, $0.1 \%$ Tween-20) was used to wash the membrane six times and then HRP-conjugated secondary antibody (dilution, 1:2,000; cat. no. ab6721; Abcam) was applied for $1 \mathrm{~h}$ at $37^{\circ} \mathrm{C}$. At the end of this incubation, the membranes were washed and proteins visualized using Enhanced ECL Chemiluminescence Substrate Kit (cat. no. 36222ES60; Shanghai Yeasen Biotechnology Co., Ltd.) and then employing the ChemiDoc imager (Bio-Rad Laboratories, Inc.). The exposure time was determined according to the brightness of the visible bands after adding the luminescent reagent, and a film was exposed. Image J v1.8.0 software (National Institutes of Health) was used to quantify the gray values of the protein bands. The gray value ratio of the target protein to GAPDH was calculated to be the relative expression of the target protein. The primary antibodies used included anti-RANK, anti-RANKL, anti-OPG, anti-E-cadherin, anti-vimentin, anti-N-cadherin and anti-GAPDH, all from Abcam (Table SII).

Statistical analysis. Statistical analyzes were performed using GraphPad Prism 6.0 Software (GraphPad Software, Inc.) from $\geq$ three independent experiments. The results were expressed as the mean $\pm \mathrm{SD}$ and data between normal and cancer tissues were compared using paired $t$ test, data among three or more groups were compared using One-way ANOVA, time-based measurement data were compared using ANOVA for repeated measurements. The Bonferroni method was performed for the post hoc test. Statistical differences between groups were indicated to be significant at $\mathrm{P}<0.05$.

\section{Results}

RANK/RANKL pathway is upregulated in CRC. To explore the possible expression pattern of components of the RANK/RANKL pathway in CRC, the expression of proteins in the RANK/RANKL pathway was measured in CRC tissues and cells. Compared with that in normal tissues, the expression levels of RANK, RANKL and OPG were all significantly elevated in cancerous tissues compared with those in normal tissues as assessed by western blotting (Fig. 1A). Furthermore, compared with those in the normal control cell line (colonic epithelial cell NCM460), RANK, RANKL and OPG all exhibited significantly higher expression levels in the five CRC cell lines tested (Fig. 1B). HT29 cells exhibited the highest expression of RANK, RANKL and OPG (Fig. 1B). These data suggest that the expression of RANK/RANKL in CRC tissues and cells was elevated compared with their non-cancerous counterparts.

Capecitabine reduces the levels of proteins in the RANK/RANKL pathway in HT29 cells. To determine the effects of capecitabine on the RANK/RANKL pathway and the optimal concentration, the expression levels of proteins in the RANK/RANKL pathway were measured in HT29 cells after treatment with ascending concentrations of capecitabine (Fig. 2). It was found that as the concentration of capecitabine increased, the expression of RANK, RANKL and OPG also decreased, where the difference became statistically significant compared with that in untreated cells (Fig. 2). These findings suggest that capecitabine may function by inhibiting the RANK/RANKL pathway. The dose range of capecitabine between 50 and $400 \mu \mathrm{M}$ could significantly reduce the expression of RANK, RANKL and OPG (Fig. 2). Furthermore, the cell viability of other CRC cells (HT29, SW480, SW620, LOVO and HCT116) decreased when the concentration of capecitabine increased. Additionally, the dose range of capecitabine between 50 and $400 \mu \mathrm{M}$ could significantly decrease cell viability (Fig. S1). Although protein expression levels and cell viability were lower after treatment with $400 \mu \mathrm{M}, 50 \mu \mathrm{M}$ was selected for subsequent experiments, as this concentration had a certain inhibitory effect on CRC cells and was non-toxic in the control cell (NCM460) group.

Capecitabine treatment and RANK knockdown can both inhibit HT29 cell proliferation. Cells were first transfected with si-RANK. To verify if RANK protein expression was knocked down after si-RANK transfection, the expression of RANK in the DMSO, si-NC and si-RANK groups was measured by western blotting. Compared with those in the si-NC group, the protein levels of RANK in the si-RANK group were lower, the difference of which was statistically significant (Fig. 3A). This finding suggests that RANK was successfully knocked down by si-RANK transfection. Functional experiments were subsequently performed to study the role of capecitabine in the RANK/RANKL pathway further in HT29 cells. Capecitabine at the dose of $50 \mu \mathrm{M}$ was applied to treat HT29 cells in parallel to si-RANK transfection. Results from MTT assay revealed that the cell viability of HT29 cells was significantly reduced after the cells were either treated with capecitabine or transfected with si-RANK compared with their respective negative controls (Fig. 3B). According to data from EdU assay, the proportion of EdU-positive cells was decreased after the HT29 cells were subjected to either capecitabine treatment or transfection with si-RANK compared with that in their corresponding negative controls (Fig. 3C). Taken together, these findings suggest that HT29 cell proliferation was inhibited by capecitabine treatment and RANK silencing. 
A
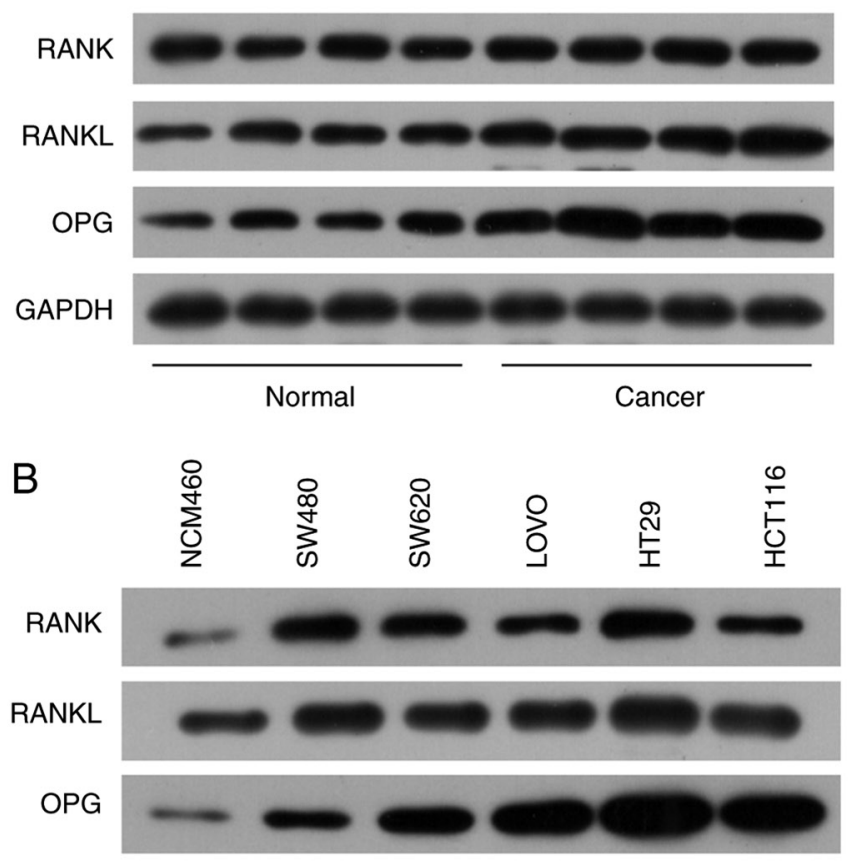

GAPDH
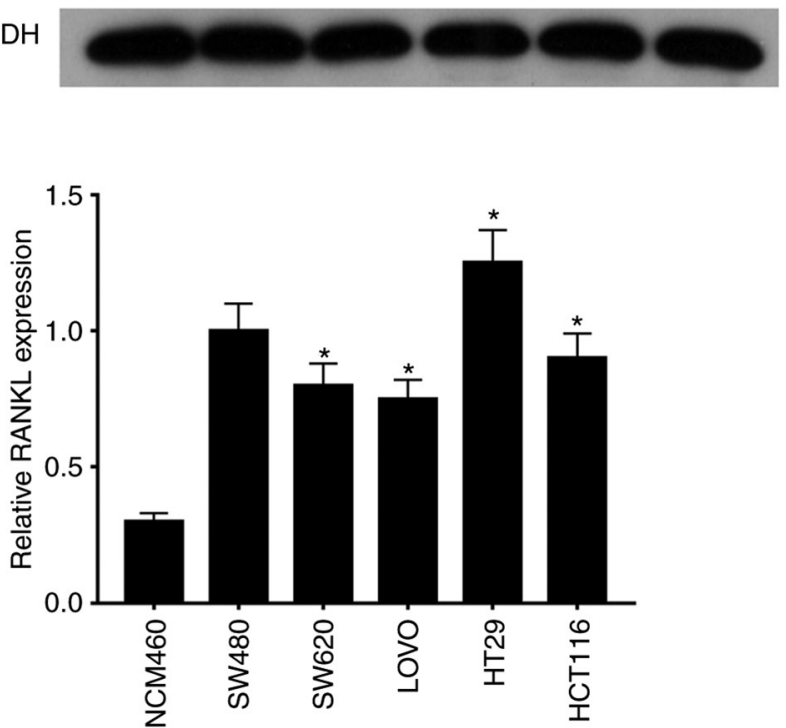
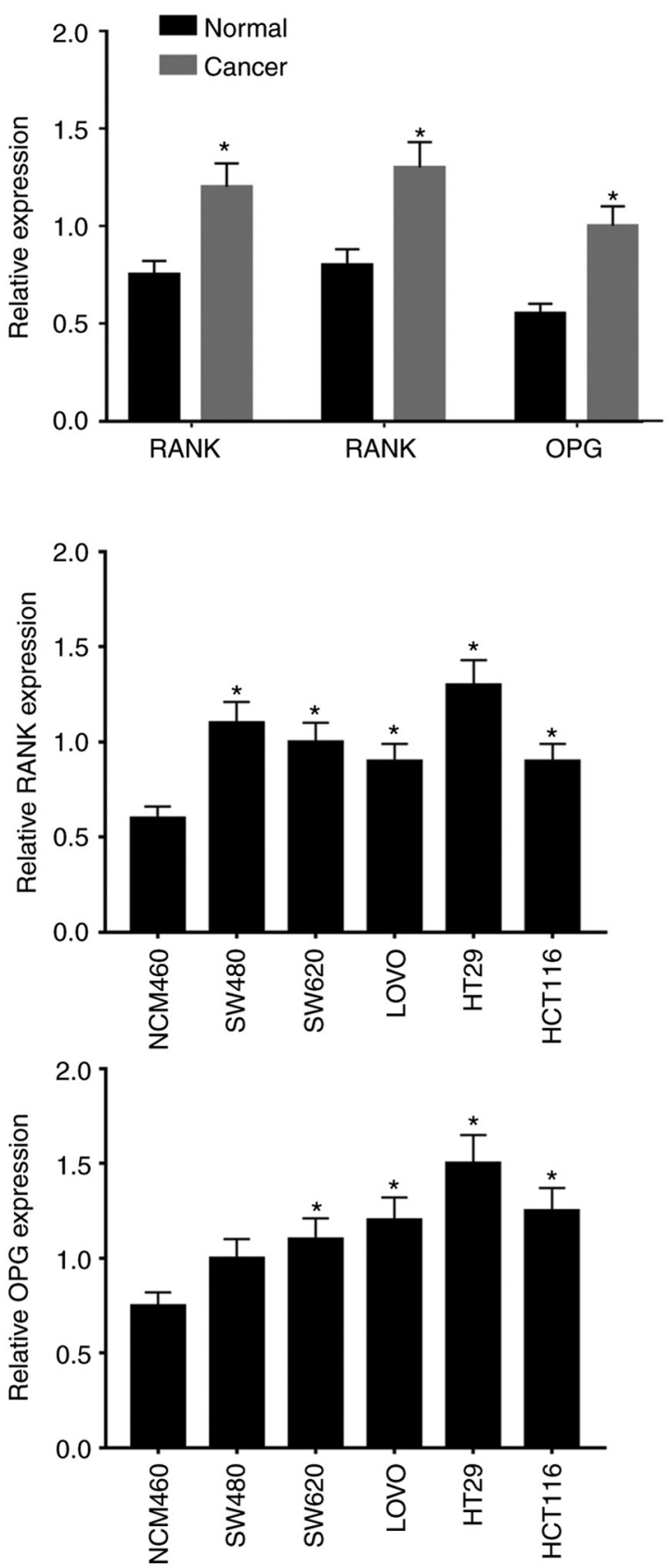

Figure 1. RANK/RANKL pathway is upregulated in colorectal cancer. (A) Western blotting analysis of RANK, RANKL and OPG proteins in cancer and adjacent normal tissues. (B) Protein expression levels of RANK, RANKL and OPG in the control cell line (colonic epithelial cell NCM460) and colorectal cancer cell lines were measured by western blotting before densitometric analyzes were determined; ${ }^{*} \mathrm{P}<0.05$ vs. Normal or NCM460. RANK, receptor activator of nuclear factor- $\kappa \mathrm{B}$; RANKL, receptor activator of nuclear factor- $\kappa \mathrm{B}$ ligand; OPG, osteoprotegerin.

Capecitabine treatment and RANK knocked down inhibit EMT in HT29 cells. To measure cell migration, Transwell and wound healing assays were performed whereas western blotting was performed to measure the expression levels of EMT-associated proteins E-cadherin, vimentin and $\mathrm{N}$-cadherin. According to results from Transwell assays, the number of migratory HT29 cells was significantly reduced after the cells were treated with capecitabine or transfected with si-RANK compared with that in their corresponding negative controls (Fig. 4A). From wound healing assays, the migration rate was found to be significantly reduced in both capecitabine-treated and si-RANK-transfected HT29 cells compared with that in their corresponding negative controls
(Fig. 4B). These two observations implicates the inhibitory effects on cell migration exerted by both capecitabine administration and RANK silencing. Compared with those in their corresponding negative controls, the protein expression levels for E-cadherin were significantly increased by the either the addition of capecitabine or silencing of RANK expression (Fig. 4C). By contrast, the protein expression levels of vimentin and $\mathrm{N}$-cadherin were significantly decreased by either the addition of capecitabine or silencing of RANK compared with those in their corresponding negative controls (Fig. 4C). These results suggest that both capecitabine and RANK knockdown can both inhibit EMT in HT29 cells. 

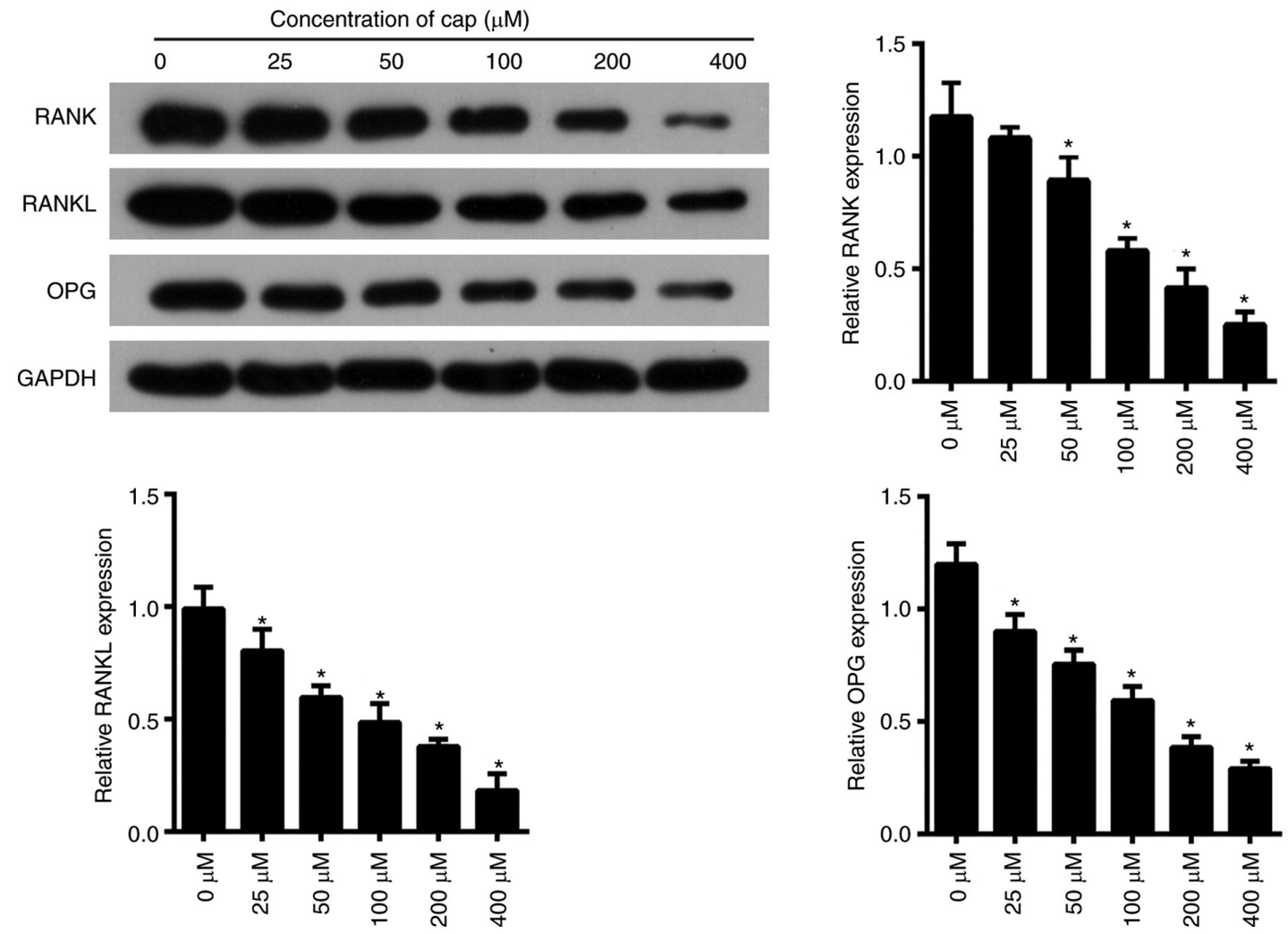

Figure 2. Capecitabine inhibits the expression levels of RANK/RANKL pathway proteins in the HT29 cell line. Western blotting was used to measure the expression of components in the RANK/RANKL pathway in HT29 cells after treatment with different concentrations of capecitabine $(0,25,50,100,200$ and $400 \mu \mathrm{M}$ ). Densitometric analyses were also performed. "P<0.05 vs. $0 \mu \mathrm{M}$. RANK, receptor activator of nuclear factor- $\mathrm{KB}$; RANKL, receptor activator of nuclear factor- $\mathrm{\kappa}$ ligand; OPG, osteoprotegerin.
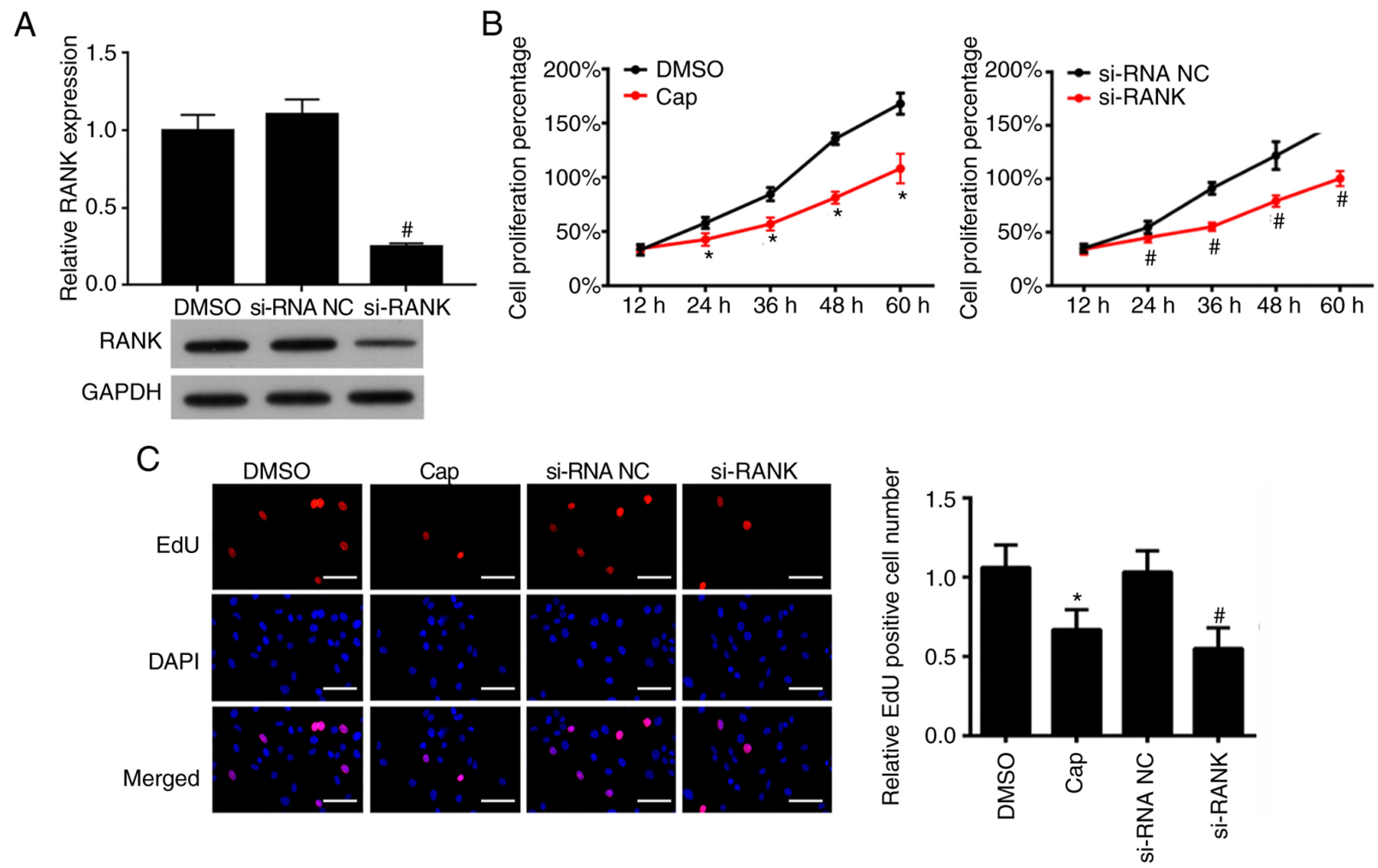

Figure 3. Both capecitabine and si-RANK transfection inhibit HT29 cell proliferation. (A) RANK expression is silenced using si-RANK before verification using western blotting. (B) Cell viability of HT29 cells treated with DMSO or capecitabine $(50 \mu \mathrm{M})$ or transfected with si-NC or si-RANK was measured using MTT assay. (C) After cell culture overnight, EdU assay was performed to measure HT29 cell proliferation after treatment with DMSO or capecitabine $(50 \mu \mathrm{M})$ or transfection with si-NC or si-RANK. Scale bar, $50 \mu \mathrm{m}$. "P $<0.05$ vs. DMSO and ${ }^{\text {"}} \mathrm{P}<0.05$ vs. si-NC. Si, small interfering; NC, negative control; RANK, receptor activator of nuclear factor- $\mathrm{kB}$; Cap, capecitabine. 
A

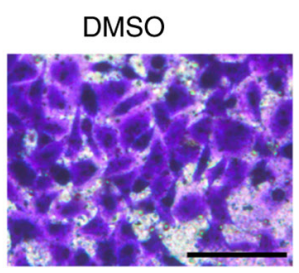

B
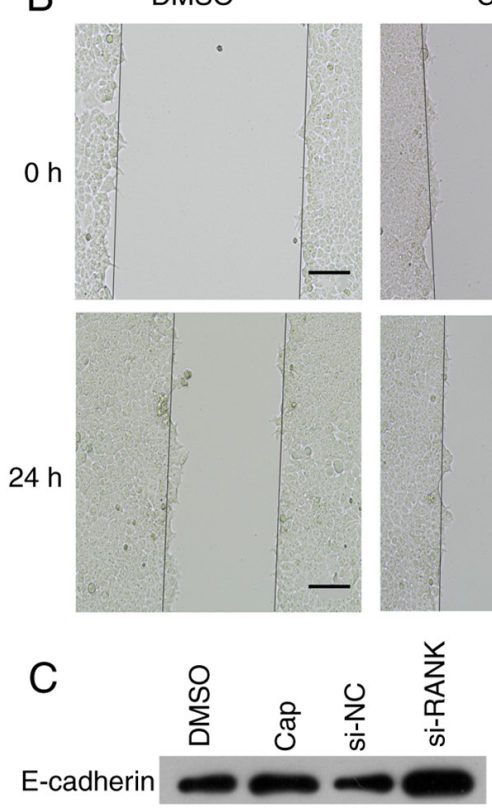

Vimentin

$\mathrm{N}$-cadherin

GAPDH

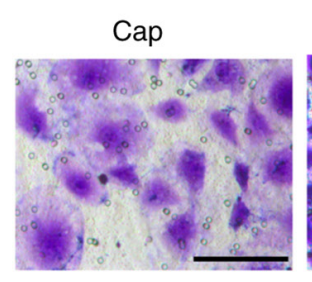

Cap
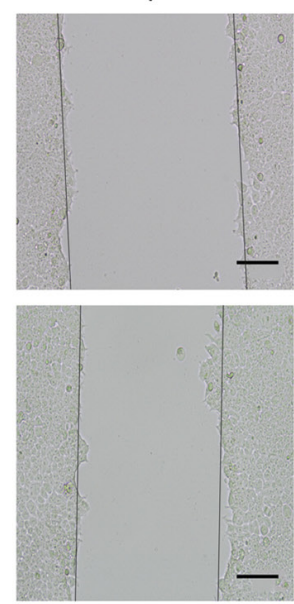

si-NC

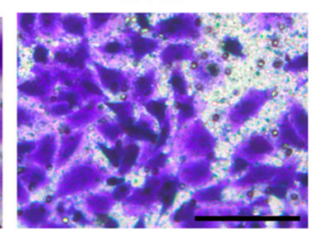

si-NC
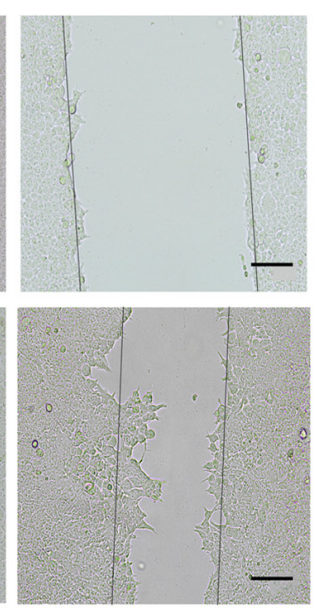

si-RANK

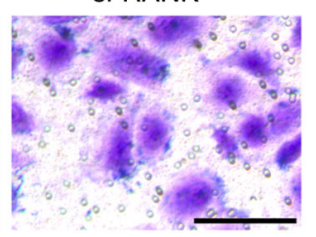

si-RANK
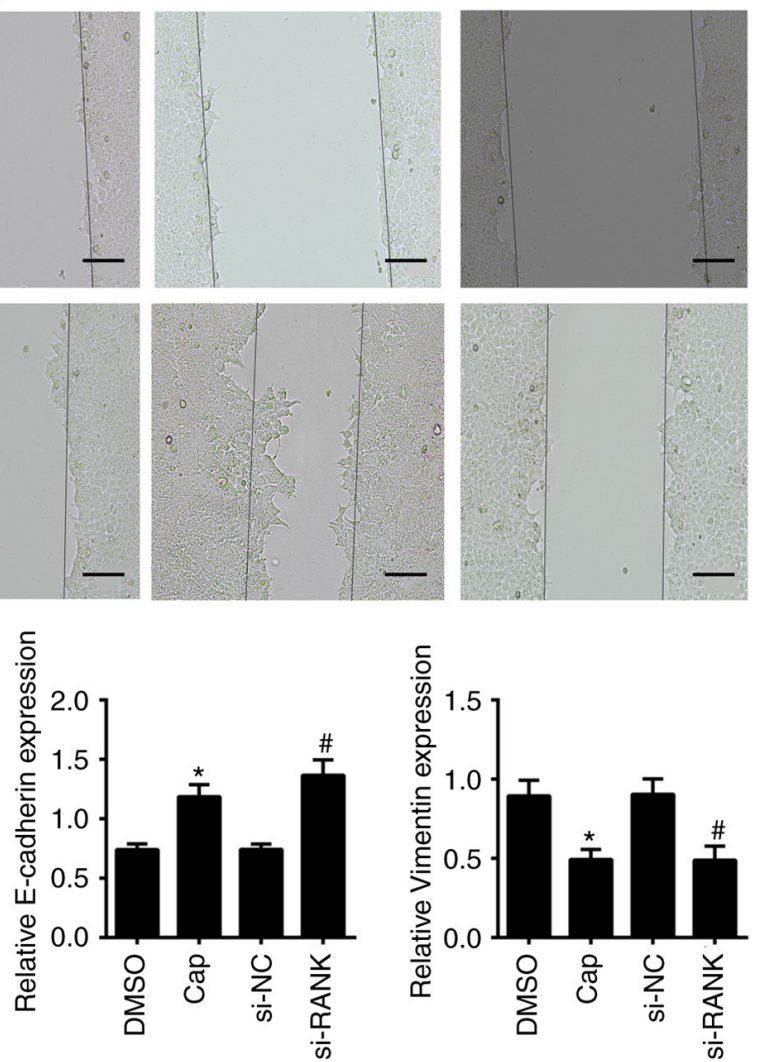
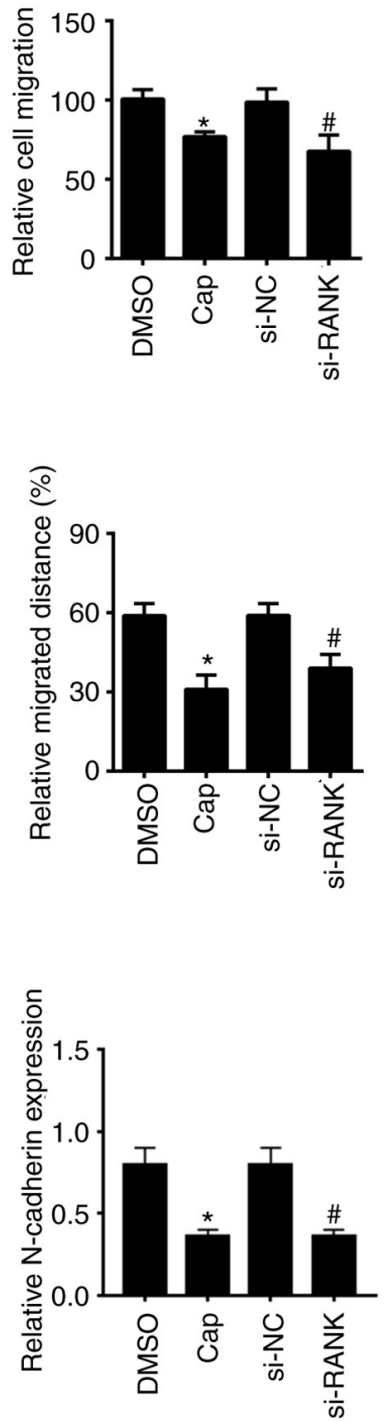

Figure 4. Both capecitabine and si-RANK transfection can inhibit EMT and migration in the HT29 cell line. After treatment with DMSO or capecitabine $(50 \mu \mathrm{M})$ or transfection with si-NC or si-RANK, the migratory ability of HT29 cells was examined using (A) Transwell and (B) wound healing assay. The concentration of capecitabine used was $50 \mu \mathrm{M}$. Scale bar, (A) $50 \mu \mathrm{m}$ or (B) $200 \mu \mathrm{m}$. (C) Epithelial-mesenchymal transition-related proteins in HT29 cells after treatment with DMSO or capecitabine $(50 \mu \mathrm{M})$ or transfection with si-NC or si-RANK, namely E-cadherin, vimentin and N-cadherin, were measured by western blotting. " $\mathrm{P}<0.05$ vs. DMSO and ${ }^{\#} \mathrm{P}<0.05$ vs. si-NC. Si, small interfering; NC, negative control; Cap, capecitabine; RANK, receptor activator of nuclear factor- $\kappa \mathrm{B}$.

RANK overexpression reverses the inhibitory effects of capecitabine on HT29 cell proliferation. To verify the effects of capecitabine on the RANK/RANKL pathway and transfection efficiency, western blotting and RT-qPCR. RANK, RANKL and OPG protein expression were all found to be inhibited by treatment with capecitabine in the Cap + pcDNA3.1 vector group and the Cap + pcDNA3.1-RANK group, but increased by transfection with pcDNA3.1-RANK in the DMSO + pcDNA3.1-RANK group and the Cap + pcDNA3.1-RANK group (Fig. 5A). After the combined intervention of capecitabine + pcDNA3.1-RANK, RANK, RANKL and OPG protein expression recovered back to their original levels in the DMSO + pcDNA3.1 vector group (Fig. 5A). Subsequently, the expression of RANK mRNA and protein in the pcDNA3.1-RANK group was significantly increased compared with that in the control group (Fig. 5B). Additionally, the expression levels of RANK mRNA in the other CRC cells (SW480, SW620, LOVO and HCT116) exhibited the same trend (Fig. S2). These results suggest that RANK overexpression was successful. Inhibition of cell viability induced by capecitabine was revealed to be significantly reversed by RANK overexpression as a result of transfection with the pcDNA3.1-RANK plasmid (Fig. 5C). By contrast, cell viability was significantly reduced in HT29 cells overexpressing RANK were treated with capecitabine compared with that in cells treated with DMSO and transfected with pcDNA3.1-RANK (Fig. 5C). EdU assay data revealed that the number of EdU-positive cells was significantly reduced after capecitabine treatment, which was significantly reversed after RANK overexpression (Fig. 5D). However, the number of EdU-positive cells was significantly reduced after the HT29 cells were treated with capecitabine and transfected with pcDNA3.1-RANK compared with that in cells treated with DMSO and transfected with pcDNA3.1-RANK (Fig. 5D). Taken together, these findings suggest that RANK overexpression counteracted the inhibitory effects of capecitabine on HT29 cell proliferation. 
A
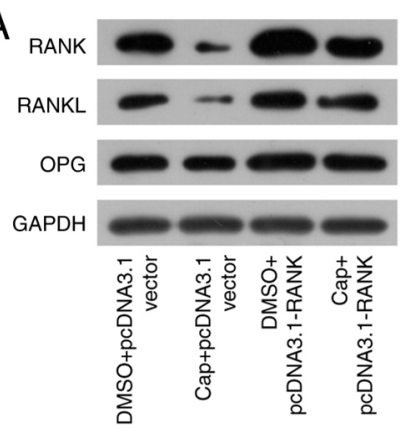

$\mathrm{B}$

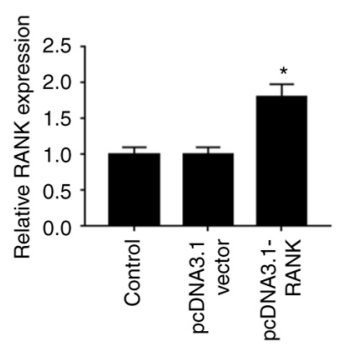

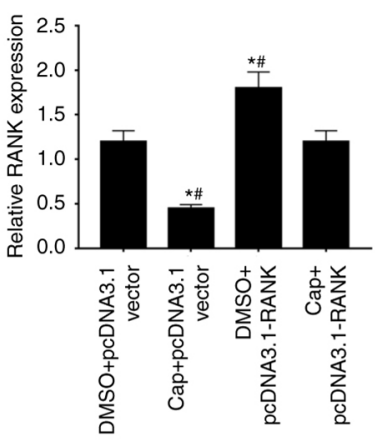

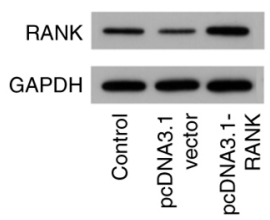

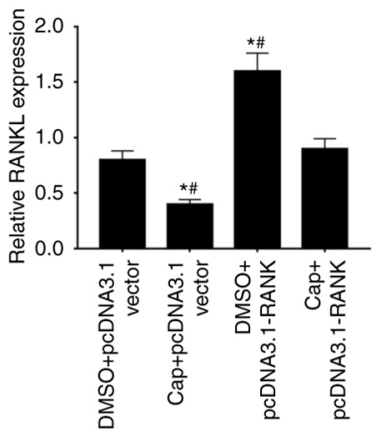

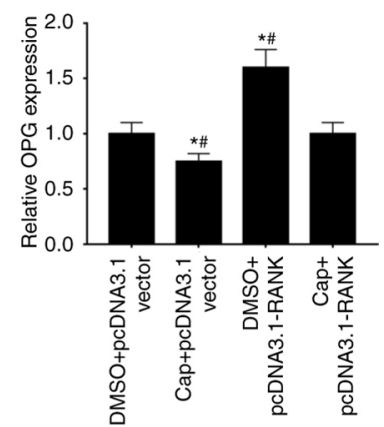

C

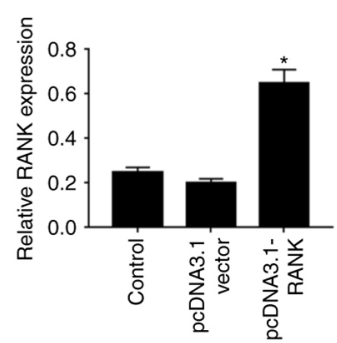

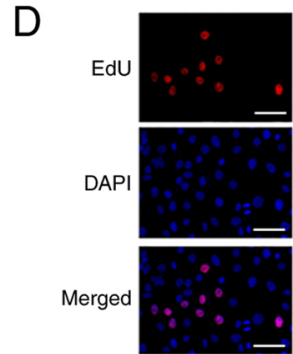

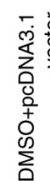

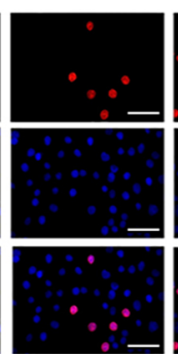

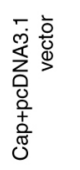

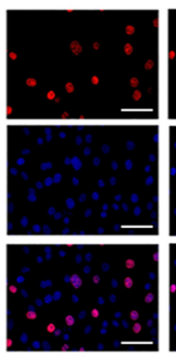

志辛
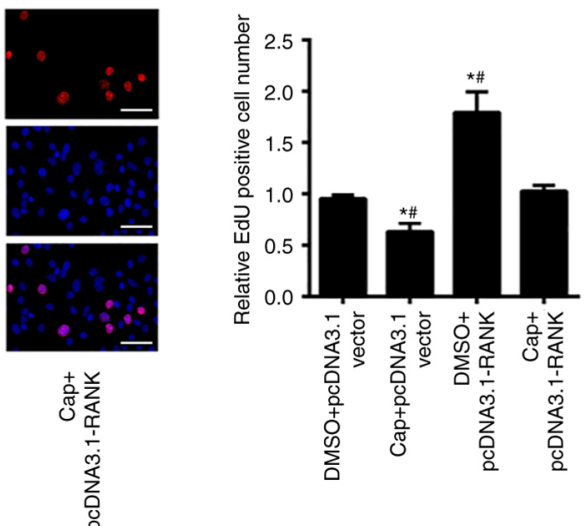

Figure 5. Overexpression of RANK reverses the inhibitory effects of capecitabine on HT29 cell proliferation. (A) HT29 cells were divided into the following four groups: DMSO + pcDNA3.1 vector; capecitabine $(50 \mu \mathrm{M})+$ pcDNA3.1 vector; DMSO + pcDNA3.1-RANK; and Cap + pcDNA3.1-RANK. The downstream protein products of the RANK/RANKL pathway were evaluated by western blotting. ${ }^{*} \mathrm{P}<0.05$ vs. DMSO + pcDNA3.1 vector and ${ }^{\sharp} \mathrm{P}<0.05$ vs. Cap + pcDNA3.1-RANK. (B) HT29 cells were divided into the following three groups: Control; pcDNA3.1 vector; and pcDNA3.1-RANK. The expression level of RANK was evaluated by reverse transcription-quantitative PCR and western blotting. ${ }^{*} \mathrm{P}<0.0001$ vs. control. Proliferation in the DMSO + pcDNA3.1 vector, capecitabine $(50 \mu \mathrm{M})+$ pcDNA3.1 vector, DMSO + pcDNA3.1-RANK and Cap + pcDNA3.1-RANK groups of HT29 cells was estimated using (C) MTT and (D) EdU assays. The concentration of capecitabine was $50 \mu \mathrm{M}$. Scale bar, $50 \mu \mathrm{m}$. ${ }^{*} \mathrm{P}<0.05$ vs. DMSO + pcDNA3.1 vector and ${ }^{\#} \mathrm{P}<0.05$ vs. Cap + pcDNA3.1-RANK. Cap, capecitabine; RANK, receptor activator of nuclear factor- $\kappa$ B; RANKL, RANK ligand; OPG, osteoprotegerin.

RANK overexpression reverses the inhibitory effects of capecitabine on EMT in HT29 cells. Expression of EMT markers were also measured in CRC cell lines (HT29, SW480, SW620, LOVO and HCT116) after they were treated with capecitabine and transfected with pcDNA3.1-RANK. According to the Transwell assays, capecitabine treatment significantly inhibited HT29 cell migration, which was significantly reversed by RANK overexpression upregulation of RANK (Fig. 6A). Simultaneous treatment with capecitabine and RANK overexpression reduced HT29 cell migration compared with that in cells treated with DMSO and transfected with pcDNA3.1-RANK (Fig. 6A). Results from wound healing assays revealed that the cell migration was also significantly inhibited by capecitabin treatment but was significantly reversed by RANK overexpression (Fig. 6B). Compared with that in cells treated with DMSO and transfected with pcDNA3.1-RANK, cell migration was significantly reduced by the simultaneous RANK overexpression and capecitabin addition (Fig. 6B). Finally, western blotting demonstrated that the capecitabin-induced increase in the protein expression of E-cadherin and capecitabin-induced decrease in the protein expression of vimentin and $\mathrm{N}$-cadherin were significantly reversed by RANK overexpression (Figs. 6C and S3). Furthermore, reductions in E-cadherin expression and elevations in vimentin and $\mathrm{N}$-cadherin induced by RANK overexpression were both significantly reversed by treatment with capecitabin (Figs. 6C and S3). In conclusion, these observations suggest that RANK overexpression reversed the suppressive effects of capecitabine on HT29 cells. 
A
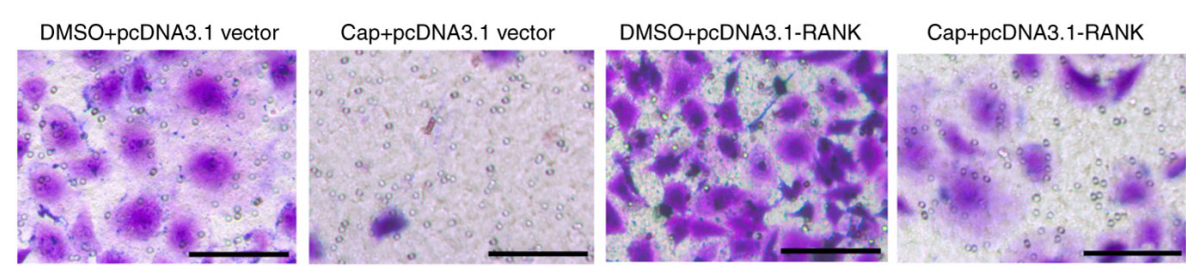

$\mathrm{B}$
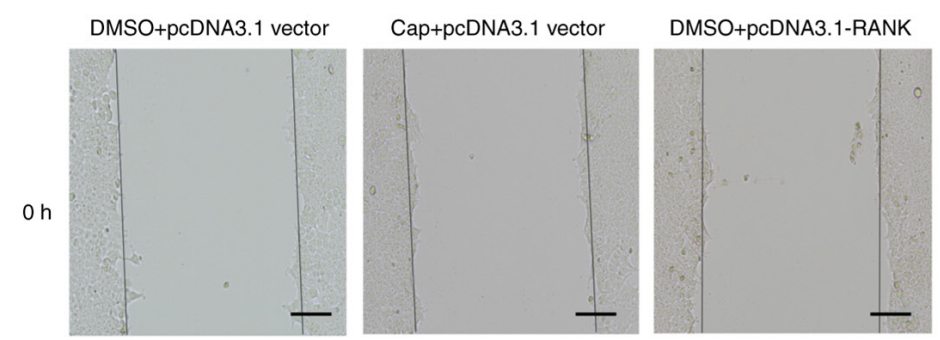

Cap+pcDNA3.1-RANK
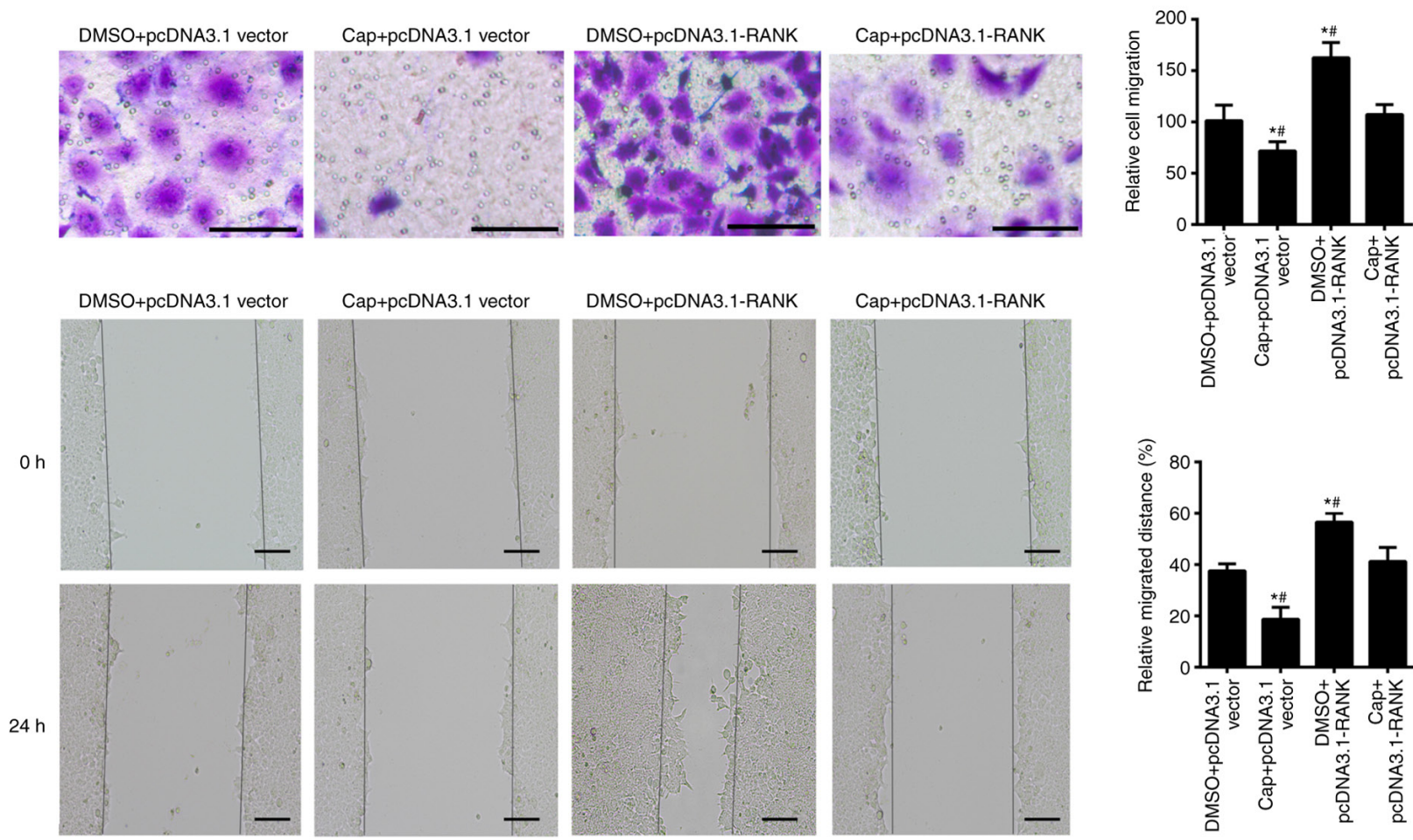

C
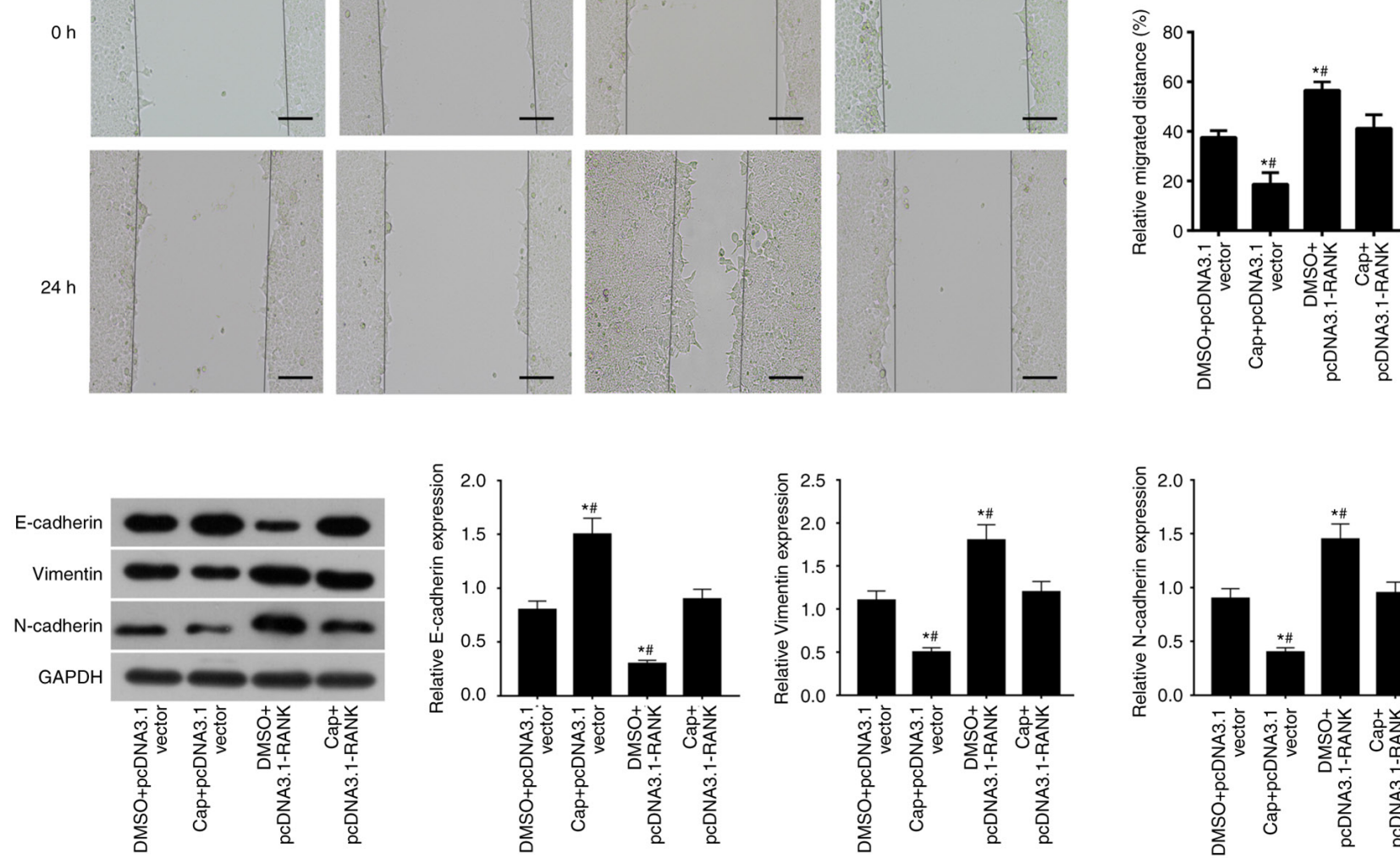

Figure 6. Overexpression of RANK reverses the inhibitory effects of capecitabine on EMT and migration in HT29 cells. The migration ability of HT29 cells in the DMSO + pcDNA3.1 vector, capecitabine $(50 \mu \mathrm{M})+$ pcDNA3.1 vector, DMSO + pcDNA3.1-RANK and Cap + pcDNA3.1-RANK groups were separately evaluated by (A) Transwell and (B) wound healing assays. The concentration of capecitabine was $50 \mu \mathrm{M}$. Scale bar, $50 \mu \mathrm{m}, 200 \mu \mathrm{m}$. (C) Western blotting was performed to assess EMT-associated proteins in HT29 cells in the DMSO + pcDNA3.1 vector, capecitabine $(50 \mu \mathrm{M})+$ pcDNA3.1 vector, DMSO + pcDNA3.1-RANK and Cap + pcDNA3.1-RANK groups. " $\mathrm{P}<0.05$ vs. DMSO + pcDNA3.1 vector and ${ }^{\prime \prime} \mathrm{P}<0.05$ vs. Cap + pcDNA3.1-RANK. Cap, capecitabine; RANK, receptor activator of nuclear factor- $\mathrm{kB}$; RANKL, RANK ligand; OPG, osteoprotegerin.

\section{Discussion}

Over the past number of decades, the rates of morbidity and mortality as a result of malignancies have been increasing worldwide (34). At present, CRC is the most prevalent malignancy in the digestive tract, where morbidity and mortality caused by this disease are increasing annually $(1,2)$. There is accumulating evidence highlighting the dysregulation of specific signaling pathways in CRC. Bone morphogenic protein 3 has been found to suppress the initiation of CRC through the activin receptor type IIB/SMAD2 and TGF- $\beta$-activated kinase $1 /$ JNK pathways (35). In addition, depletion of kinesin family member 22 can attenuates the colon carcinoma proliferation and tumor growth (36). Proline rich 14 upregulation can facilitate the growth, EMT progression and metastasis of CRC through the AKT pathway (37). Among the signaling pathways that have been shown to be aberrantly dysregulated in CRC, the RANK/RANKL pathway was focused upon in the present study. The RANK/RANKL pathway has been implicated in the development of several types of cancer, including breast cancer (38), myeloma (39) and endometrial cancer (40). The present study demonstrated that the RANK/RANKL pathway was upregulated in CRC, suggesting that this pathway was involved in its pathogenesis.

CRC typically becomes refractory to chemotherapy treatment whilst retaining its malignancy (41). This results in poor chemotherapeutic efficacy and survival rates in patients with CRC (42). Therefore, discovery of novel treatments that are effective is vital for improving patient outcome. Capecitabine is a fluorouracil derivative chemotherapeutic drug that can prolong the period of high 5-FU sensitivity 
in breast cancer and gastric cancer cells (43). In addition, previous studies have confirmed that $5-\mathrm{FU}$ is involved in regulating RANKL signaling and hence osteoclast differentiation (44). This suggests that the effects exerted by capecitabine may be associated with the RANK/RANKL pathway. At present, capecitabine is known as a 'failure agent' for treating patients with CRC $(13,14)$. Therefore, the present study investigated the potential effects of capecitabine on CRC with specific focus on the RANK/RANKL pathway. Through the measurement of the expression of proteins in the RANK/RANKL signaling pathway in multiple CRC cell lines and tissues, it was found that RANK, RANKL and OPG expression were all increased compared with that in their corresponding controls, suggesting that the occurrence of CRC was closely associated with activation of the RANK/RAKL signaling pathway. Furthermore, following treatment of HT29 cells with different concentrations of capecitabine, it was found that capecitabine mediated an inhibitory effect on the expression of RANK/RANKL pathway proteins. It was also found that the silencing of RANK expression could inhibit HT29 cell proliferation. By contrast, after RANK was overexpressed, the proliferation of HT29 cells was increased significantly, which can in turn be reversed by capecitabine. These findings implicate a suppressive function for capecitabine in CRC and to the best of our knowledge, the present study was the first to reveal a promotional role for the RANK/RANKL pathway in CRC. The present study demonstrated that capecitabine could inactivate the RANK/RANKL pathway in CRC cells. The present study found that capecitabine and the RANK/RANKL pathway mediated opposite functions in CRC. Therefore, the hypothesis that resistance to capecitabine typically observed in CRC was due to an activated RANK/RANKL pathway was tested. Rescue experiments revealed that stimulation of the RANK/RANKL pathway reversed the inhibitory effects of capecitabine on CRC proliferation and EMT.

In the present study, it was found that the failure of capecitabine chemotherapy in CRC was at least in part attributed to the upregulated activation of the RANK/RANKL pathway. In the present study, high expression levels of RANK were detected in CRC tumor tissues. In conclusion, capecitabine inhibited EMT and proliferation in CRC through modulation of the RANK/RANKL pathway. Therefore, to treat patients more effectively, capecitabine chemotherapy combined with a RANK-targeted therapy would be desirable.

There remain a number of limitations to the present study. Only in vitro studies were performed. Ideally, further studies in animal models of CRC should be performed. Furthermore, the precise modulatory mechanism between capecitabine and the RANK/RANKL pathway in CRC is required clinically. Future investigations should focus on deepening understanding into the detailed mechanism between capecitabine and the RANK/RANKL pathway in CRC both in vitro and in vivo, in addition to identifying novel diagnostic and prognostic markers.

\section{Acknowledgements}

Not applicable.

\section{Funding}

The present study was supported by the Science and Technology Agency of Taizhou City of Zhejiang Province (grant no. 131KY13).

\section{Availability of data and materials}

The data used to support the findings of this study are available from the corresponding author upon request.

\section{Authors' contributions}

MS and XM were responsible for the concept and study design. $\mathrm{CJ}$ and $\mathrm{CY}$ were responsible for performing the experiments, data collection and raw data authentication. $\mathrm{HJ}$ and $\mathrm{YW}$ were responsible for data analysis and interpretation. All authors have read and approved the final manuscript.

\section{Ethics approval and consent to participate}

The Ethics Committee of Taizhou Hospital of Zhejiang Province affiliated to Wenzhou Medical University reviewed and approved the present study. Each patient had provided appropriately signed consent forms.

\section{Patient consent for publication}

Not applicable.

\section{Competing interests}

The authors declare that they have no competing interests.

\section{References}

1. Arnold M, Sierra MS, Laversanne M, Soerjomataram I, Jemal A and Bray F: Global patterns and trends in colorectal cancer incidence and mortality. Gut 66: 683-691, 2017.

2. Torre LA, Bray F, Siegel RL, Ferlay J,Lortet-Tieulent J and Jemal A: Global cancer statistics, 2012. CA Cancer J Clin 65: 87-108, 2015.

3. Carethers JM and Doubeni CA: Causes of socioeconomic disparities in colorectal cancer and intervention framework and strategies. Gastroenterology 158: 354-367, 2020.

4. Sivamaruthi BS, Kesika P and Chaiyasut C: The role of probiotics in colorectal cancer management. Evid Based Complement Alternat Med: Feb 14, 2020 (Epub ahead of print). doi: $10.1155 / 2020 / 3535982$.

5. Müller MF, Ibrahim AE and Arends MJ: Molecular pathological classification of colorectal cancer. Virchows Arch 469: 125-134, 2016.

6. Quan Y,Xu M, Cui P, Ye M,Zhuang B and Min Z: Grainyhead-like 2 promotes tumor growth and is associated with poor prognosis in colorectal cancer. J Cancer 6: 342-350, 2015.

7. Wang Y, Wang L, Wang W and Guo X: Overexpression of circular RNA hsa_circ_0001038 promotes cervical cancer cell progression by acting as a ceRNA for miR-337-3p to regulate cyclin-M3 and metastasis-associated in colon cancer 1 expression. Gene 733: 144273, 2020.

8. De Falco V, Napolitano S, Roselló S, Huerta M, Cervantes A, Ciardiello $\mathrm{F}$ and Troiani T: How we treat metastatic colorectal cancer. ESMO Open 4 (Suppl 2): e000813, 2020.

9. Thorat SG, Chikhale RV and Tajne MR: Development and validation of HPLC and HPTLC methods for therapeutic drug monitoring of capecitabine in colorectal cancer patients. J Chromatogr Sci 57: 892-900, 2019.

10. Kim JH: Chemotherapy for colorectal cancer in the elderly. World J Gastroenterol 21: 5158-5166, 2015. 
11. Aglago EK, Huybrechts I, Murphy N, Casagrande C, Nicolas G, Pischon T, Fedirko V, Severi G, Boutron-Ruault MC, Fournier A, et al: Consumption of fish and long-chain n-3 polyunsaturated fatty acids is associated with reduced risk of colorectal cancer in a large european cohort. Clin Gastroenterol Hepatol 18: 654-66.e6, 2020.

12. Van Cutsem E, Verslype C and Tejpar S: Oral capecitabine: Bridging the Atlantic divide in colon cancer treatment. Semin Oncol 32: 43-51, 2005.

13. Chen Q, Mao Y, Meng F, Wang L, Zhang H, Wang W and Hua D: Rs7911488 modified the efficacy of capecitabine-based therapy in colon cancer through altering miR-1307-3p and TYMS expression. Oncotarget 8: 74312-74319, 2017.

14. Hirsch BR and Zafar SY: Capecitabine in the management of colorectal cancer. Cancer Manag Res 3: 79-89, 2011.

15. Silva I and Branco JC: Rank/Rank1/opg: Literature review. Acta Reumatol Port 36: 209-218, 2011.

16. Khosla S: Minireview: The OPG/RANKL/RANK system. Endocrinology 142: 5050-5055, 2001.

17. Sisay M, Mengistu G and Edessa D: The RANK/RANKL/OPG system in tumorigenesis and metastasis of cancer stem cell: Potential targets for anticancer therapy. Onco Targets Ther 10 3801-3810, 2017

18. Luo G, Li F, Li X, Wang ZG and Zhang B: TNF $\alpha$ and RANKL promote osteoclastogenesis by upregulating RANK via the NFкB pathway. Mol Med Rep 17: 6605-6611, 2018.

19. Wood MB, Rios D and Williams IR: TNF- $\alpha$ augments RANKL-dependent intestinal $\mathrm{M}$ cell differentiation in enteroid cultures. Am J Physiol Cell Physiol 311: C498-C507, 2016.

20. Chu GC, Zhau HE, Wang R, Rogatko A, Feng X, Zayzafoon M, Liu Y, Farach-Carson MC, You S, Kim J, et al: RANK- and c-Met-mediated signal network promotes prostate cancer metastatic colonization. Endocr Relat Cancer 21: 311-326, 2014

21. Casimiro S, Mohammad KS, Pires R, Tato-Costa J, Alho I, Teixeira R, Carvalho A, Ribeiro S, Lipton A, Guise TA and Costa L: RANKL/RANK/MMP-1 molecular triad contributes to the metastatic phenotype of breast and prostate cancer cells in vitro. PLoS ONE 8: e63153, 2013.

22. Buckle CH, Neville-Webbe HL, Croucher PI and Lawson MA Targeting RANK/RANKL in the treatment of solid tumours and myeloma. Curr Pharm Des 16: 1272-1283, 2010.

23. Okimoto G, Zeinalzadeh A, Wenska T, Loomis M, Nation JB, Fabre T, Tiirikainen M, Hernandez B, Chan O, Wong L and Kwee S: Joint analysis of multiple high-dimensional data types using sparse matrix approximations of rank-1 with applications to ovarian and liver cancer. BioData Min 9: 24, 2016.

24. Khan MA, Sharif M, Akram T, Yasmin M and Nayak RS: Stomach deformities recognition using rank-based deep features selection. J Med Syst 43: 329, 2019.

25. Infante M, Fabi A, Cognetti F, Gorini S, Caprio M and Fabbri A: RANKL/RANK/OPG system beyond bone remodeling: Involvement in breast cancer and clinical perspectives. J Exp Clin Cancer Res 38: 12, 2019.

26. Sood SK, Balasubramanian S, Higham S, Fernando M and Harrison B: Osteoprotegerin (OPG) and related proteins (RANK, RANKL and TRAIL) in thyroid disease. World J Surg 35: 1984-1992, 2011.

27. Retraction: Antitumor and antimetastatic activities of docetaxel are enhanced by genistein through regulation of osteoprotegerin/receptor activator of nuclear factor- $\kappa \mathrm{B}$ (RANK)/RANK Ligand/MMP-9 signaling in prostate cancer. Cancer Res 78: 5475,2018

28. Pritchard L, Cardle L, Quinn S and Dufton M: Simple intrasequence difference (SID) analysis: An original method to highlight and rank sub-structural interfaces in protein folds. Application to the folds of bovine pancreatic trypsin inhibitor, phospholipase A2, chymotrypsin and carboxypeptidase A. Protein Eng 16 $87-101,2003$
29. Liang Q, Wang Y, Lu Y, Zhu Q, Xie W, Tang N, Huang L, An T, Zhang D, Yan A, et al: RANK promotes colorectal cancer migration and invasion by activating the $\mathrm{Ca}(2+)$-calcineurin/NFATC1-ACP5 axis. Cell Death Dis 12: 336, 2021.

30. Zhao W, Chen B, Guo X, Wang R, Chang Z, Dong Y, Song K, Wang W, Qi L, Gu Y, et al: A rank-based transcriptional signature for predicting relapse risk of stage II colorectal cancer identified with proper data sources. Oncotarget 7: 19060-19071, 2016.

31. National Health Commission of the People's Republic of China: [Chinese Protocol of Diagnosis and Treatment of Colorectal Cancer (2020 edition)]. Zhonghua Wai Ke Za Zhi 58: 561-585, 2020 (In Chinese).

32. Livak KJ and Schmittgen TD: Analysis of relative gene expression data using real-time quantitative PCR and the 2(-Delta Delta C(T)) method. Methods 25: 402-408, 2001.

33. Park DW, Ham YM, Lee YG, So R, Seo YJ and Kang SC: Multioside, an active ingredient from adonis amurensis, displays anti-cancer activity through autophagosome formation. Phytomedicine 65: 153114, 2019.

34. Choi MY, Flood K, Bernatsky S, Ramsey-Goldman R and Clarke AE: A review on SLE and malignancy. Best Pract Res Clin Rheumatol 31: 373-396, 2017.

35. Wen J, Liu X, Qi Y, Niu F, Niu Z, Geng W, Zou Z, Huang R, Wang $J$ and Zou H: BMP3 suppresses colon tumorigenesis via ActRIIB/SMAD2-dependent and TAK1/JNK signaling pathways. J Exp Clin Cancer Res 38: 428, 2019.

36. Li B, Zhu FC, Yu SX, Liu SJ and Li BY: Suppression of KIF22 inhibits cell proliferation and xenograft tumor growth in colon cancer. Cancer Biother Radiopharm 35: 50-57, 2019.

37. Li F, Zhang C and Fu L: PRR14 overexpression promotes cell growth, epithelial to mesenchymal transition and metastasis of colon cancer via the AKT pathway. PLoS ONE 14: e0218839, 2019.

38. Kiesel L and Kohl A: Role of the RANK/RANKL pathway in breast cancer. Maturitas 86: 10-16, 2016

39. Tsubaki M, Takeda T, Yoshizumi M, Ueda E, Itoh T, Imano M, Satou T and Nishida S: RANK-RANKL interactions are involved in cell adhesion-mediated drug resistance in multiple myeloma cell lines. Tumour Biol 37: 9099-9110, 2016.

40. Wang J, Sun X, Zhang H, Wang Y and Li Y: MPA influences tumor cell proliferation, migration, and invasion induced by RANKL through PRB involving the MAPK pathway in endometrial cancer. Oncol Rep 33: 799-809, 2015.

41. Yamaue H, Tanimura H, Nakamori M, Noguchi K, Iwahashi M, Tani M, Hotta T, Murakami K and Ishimoto K: Clinical evaluation of chemosensitivity testing for patients with colorectal cancer using MTT assay. Dis Colon Rectum 39: 416-422, 1996.

42. Singh G, Graffner HO, Milsom JW and Chaudry IH: Tauromustine is more effective than conventional chemotherapy in the treatment of colonic tumors. Dis Colon Rectum 36: 394-399, 1993.

43. Lam SW, Guchelaar HJ and Boven E: The role of pharmacogenetics in capecitabine efficacy and toxicity. Cancer Treat Rev 50: 9-22, 2016.

44. Song D, Meng T, Xu W, Hou T, Lin Z, Yin H,Li B, Zhou L, Wang T, Han S, et al: 5-Fluoruracil blocked giant cell tumor progression by suppressing osteoclastogenesis through NF-kappaB signals and blocking angiogenesis. Bone 78: 46-54, 2015.

This work is licensed under a Creative Commons Attribution-NonCommercial-NoDerivatives 4.0 International (CC BY-NC-ND 4.0) License. 